Open Access

\title{
Daily estimation of the severity of organ dysfunctions in critically ill children by using the PELOD-2 score
}

Stéphane Leteurtre ${ }^{1,2^{*}}$, Alain Duhamel ${ }^{2,3}$, Valérie Deken ${ }^{2,3}$, Jacques Lacroix ${ }^{4}$, and Francis Leclerc ${ }^{1,2}$ (D) on behalf of the Groupe Francophone de Réanimation et Urgences Pédiatriques (GFRUP)

\begin{abstract}
Introduction: Daily or serial evaluation of multiple organ dysfunction syndrome (MODS) scores may provide useful information. We aimed to validate the daily (d) PELOD-2 score using the set of seven days proposed with the previous version of the score.

Methods: In all consecutive patients admitted to nine pediatric intensive care units (PICUs) we prospectively measured the dPELOD-2 score at day 1, 2, 5, 8, 12, 16, and 18. PICU mortality was used as the outcome dependent variable. The discriminant power of the dPELOD-2 scores was estimated using the area under the ROC curve and the calibration using the Hosmer-Lemeshow chi-square test. We used a logistic regression to investigate the relationship between the dPELOD-2 scores and outcome, and between the change in PELOD-2 score from day 1 and outcome.
\end{abstract}

Results: We included 3669 patients (median age 15.5 months, mortality rate $6.1 \%$, median length of PICU stay 3 days). Median dPELOD-2 scores were significantly higher in nonsurvivors than in survivors $(p<0.0001)$. The dPELOD-2 score was available at least at day 2 in 2057 patients: among the 796 patients without MODS on day 1 , 186 (23.3 \%) acquired the syndrome during their PICU stay (mortality $4.9 \%$ vs. $0.3 \%$ among the 610 who did not; $p<0.0001)$. Among the1261 patients with MODS on day1, the syndrome worsened in $157(12.4 \%)$ and remained unchanged or improved in 1104 (87.6\%) (mortality $22.9 \%$ vs. $6.6 \% ; p<0.0001$ ). The AUC of the dPELOD-2 scores ranged from 0.75 (95 \% Cl: 0.67-0.83) to 0.89 (95\% Cl: 0.86-0.91). The calibration was good with a chi-square test between $13.5(p=0.06)$ and $0.9(p=0.99)$. The PELOD-2 score on day 1 was a significant prognostic factor; the serial evaluation of the change in the dPELOD-2 score from day1, adjusted for baseline value, demonstrated a significant odds ratio of death for each of the 7 days.

Conclusion: This study suggests that the progression of the severity of organ dysfunctions can be evaluated by measuring the dPELOD-2 score during a set of 7 days in PICU, providing useful information on outcome in critically ill children. Its external validation would be useful.

\footnotetext{
* Correspondence: stephane.leteurtre@chru-lille.fr

These data were presented in part, at the 24th annual meeting of the

European Society of Paediatric and Neonatal Intensive Care on June 12-15,

2013, Rotterdam, Netherlands and at the 42nd international meeting of the

Société de Réanimation de Langue Française on 15-17 January, 2014, Paris,

France.

'Pediatric Intensive Care Unit, Jeanne de Flandre University Hospital, 2

avenue Eugène Avinée, 59037 Lille, Cedex, France

${ }^{2}$ EA 2694, Public Health: Epidemiology and Quality of Care, University of Lille

2, Lille, France

Full list of author information is available at the end of the article
}

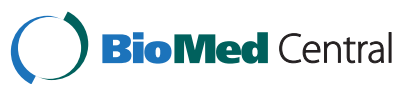

(c) 2015 Leteurtre et al. Open Access This article is distributed under the terms of the Creative Commons Attribution 4.0 International License (http://creativecommons.org/licenses/by/4.0/), which permits unrestricted use, distribution, and reproduction in any medium, provided you give appropriate credit to the original author(s) and the source, provide a link to the Creative Commons license, and indicate if changes were made. The Creative Commons Public Domain Dedication waiver (http://creativecommons.org/publicdomain/zero/1.0/) applies to the data made available in this article, unless otherwise stated. 


\section{Introduction}

In the intensive care unit (ICU), almost all adult and pediatric patients present some organ dysfunction [1-5] and mortality rates increase with the number of organ dysfunctions [5-8]. Organ dysfunction scores were developed in critically ill adults and children to describe and quantify the severity of organ dysfunctions throughout the ICU stay. These scores are frequently used as an outcome variable in clinical trials [9-11]. In 2003 we developed and validated a multiple organ dysfunction syndrome (MODS) score for critically ill children: the pediatric logistic organ dysfunction (PELOD) score using the most abnormal value of each variable during the entire pediatric ICU (PICU) stay [12]. In 2010, considering that measurements repeated daily may provide more useful information, we identified a set of 7 days as the optimal period for measurement of the daily PELOD score [13]. In 2013, using a larger and more recent database, we developed and validated the PELOD-2 score, which, contrary to the first version, uses a continuous scale [14]. The objective of this study was to validate the daily PELOD-2 (dPELOD-2) score using the set of 7 days proposed with the previous version of the PELOD score [13].

\section{Materials and methods}

All consecutive patients admitted between June 2006 and October 2007, to nine multidisciplinary, tertiary-care PICUs of university-affiliated hospitals (eight French and oneBelgian, all member of the Groupe Francophone de Réanimation et Urgences Pédiatriques-GFRUP) were prospectively included. Exclusion criteria were: age 18 years or older; premature at entry into PICU; pregnancy; total length of stay in PICU less than $4 \mathrm{~h}$; admission in a state of continuous cardiopulmonary resuscitation without achieving stable vital signs for at least $2 \mathrm{~h}$; transfer from another PICU; and admissions for scheduled procedures normally performed in other hospital locations. The study and its database were declared safe and were approved by the French authorities (Commission Nationale de l'Informatique et des Libertés) on 7 February 2007. The study design was approved by the ethics committee of the Société de Réanimation de Langue Française on 27 April 2007 for all the participating hospitals. The requirement for consent was waived because the study was strictly observational.

We collected baseline characteristics and calculated dPELOD-2 score at days $1,2,5,8,12,16$ and 18 in PICU. The PICU day 1 started from admission time to $\mathrm{H} 24$, and so on. Length of PICU stay was defined as the difference between admission day and discharge day plus 1. For each variable, the most abnormal value each day was used in calculating the dPELOD-2 score [12, 14]. Variables were measured only if requested by the attending physician (i.e., if justified by clinical status of patient). Every day, if a variable was not measured, we assumed that it was identical to the previous measurement (i.e., the physician considered that the value of the variable did not change) or normal (i.e., the physician considered that the value of the variable was normal) $[12,14]$. Organ dysfunction was defined as a PELOD-2 score $>0$ for a given organ, and MODS as the simultaneous presence of two or more organ dysfunctions The PICU discharge status (death/survival) was used as the outcome dependent variable.

\section{Statistical analysis}

All statistical analyses were performed with SAS software (SAS institute Inc., Cary, NC, USA). A $p$ value $<0.05$ was considered statistically significant. Results are expressed as frequencies and percentages for categorical variables and as median and interquartile range (IQR) for quantitative variables. The comparisons between the two groups of outcomes and the quantitative variables were performed using the Wilcoxon signed rank test. The relationships between the outcome and the categorical variables were analyzed using the chi-square test or Fischer's exact probability test.

The discriminant power of the dPELOD-2 scores was estimated using the area under the receiver-operating characteristics curve (AUC) (with $95 \%$ confidence interval) and the calibration was assessed using the HosmerLemeshow chi-square test. We used logistic regression to investigate the relationship (1) between the dPELOD2 scores and outcome, and (2) between the change in PELOD-2 score from day 1 and outcome.

\section{Results}

The study included 3,669 patients, two patients of the original database [14] with incomplete data being excluded. Characteristics of the population are reported in Table 1. The mortality rate was $6.1 \%$ (222 deaths). Administrative median length of stay in PICU was 3 days [2-6] in survivors and 4 days [2-12] in non survivors $(p=0.055)$.

Daily PELOD-2 score was measured on 7,983 days (Fig. 1). MODS was present on day 1 in 2,024 of the patients in the whole population (55.2\%). The dPELOD-2 score was available at least at day 2 in 2,057 patients (Fig. 1) allowing the identification of new and progressive MODS: among the 796 patients without MODS (one or no organ dysfunction) on day 1, 186 (23.3 \%) acquired the syndrome during their PICU stay (new MODS); the mortality rate was $4.9 \%$ among these children, as compared with $0.3 \%$ among the 610 who did not acquire the syndrome during their stay $(p<0.0001)$. Among the 1,261 patients with MODS on day 1, the syndrome worsened during PICU stay in 157 (12.4 \%) 
Table 1 Population characteristics

\begin{tabular}{|c|c|}
\hline Variable & Value \\
\hline Total number of patients & 3,669 \\
\hline \multicolumn{2}{|l|}{ Baseline characteristics } \\
\hline Gender, male, n (\%) & $2096(57.1)$ \\
\hline Age, months, median (IQR) & $15.5(2.2 ; 70.7)$ \\
\hline 0 to $<1$ months, $\mathrm{n}(\%)$ & $627(17.1)$ \\
\hline 1 to 11 months, $\mathrm{n}(\%)$ & $1067(29.1)$ \\
\hline 12 to 23 months, $\mathrm{n}(\%)$ & $398(10.9)$ \\
\hline 24 to 59 months, n (\%) & $559(15.2)$ \\
\hline 60 to 143 months, n (\%) & $562(15.3)$ \\
\hline$\geq 144$ months, $\mathrm{n}(\%)$ & $456(12.4)$ \\
\hline Recovery post procedure, $\mathrm{n}(\%)^{\mathrm{a}}$ & $955(26.0)$ \\
\hline PIM2 score, predicted death rate in \%, median (IQR) & $1.43(0.78 ; 4.33)$ \\
\hline \multicolumn{2}{|l|}{ Primary reason for PICU admission, $\mathrm{n}(\%)$} \\
\hline Respiratory & $1663(45.3)$ \\
\hline Neurological & $662(18.0)$ \\
\hline Cardiovascular & $672(18.3)$ \\
\hline Hepatic & $40(1.1)$ \\
\hline Genitourinary & $96(2.6)$ \\
\hline Gastrointestinal & $205(5.6)$ \\
\hline Endocrine & $57(1.6)$ \\
\hline Musculoskeletal & $45(1.2)$ \\
\hline Hematological & $45(1.2)$ \\
\hline Miscellaneous/undetermined & $99(2.7)$ \\
\hline Mixed & $85(2.3)$ \\
\hline \multicolumn{2}{|l|}{ Cause of primary diseases at entry, $\mathrm{n}(\%)$} \\
\hline Infection & $862(23.5)$ \\
\hline Trauma & $324(8.8)$ \\
\hline Congenital disease & $1123(30.6)$ \\
\hline Drug poisoning & $72(2.0)$ \\
\hline Cancer & $120(3.3)$ \\
\hline Diabetes & $41(1.1)$ \\
\hline Allergic/immunologic diseases & $55(1.5)$ \\
\hline Miscellaneous/undetermined & $1072(29.2)$ \\
\hline Elective PICU admission, $\mathrm{n}(\%)^{\mathrm{a}}$ & $970(26.4)$ \\
\hline \multicolumn{2}{|l|}{ Outcomes } \\
\hline Mechanical ventilation, n (\%) & $1926(52.5)$ \\
\hline Length of ICU stay, days, median (IQR) & $3(2 ; 6)$ \\
\hline Mortality, n (\%) & $222(6.1)$ \\
\hline
\end{tabular}

${ }^{a}$ According to pediatric index of mortality (PIM2) instructions. IQR interquartile range, PICU pediatric intensive care unit

(progressive MODS) and remained unchanged or improved in 1,104 (87.6\%); the mortality rate was $22.9 \%$ among those in whom it worsened and $6.6 \%$ among the other children; $p<0.0001$ ). New or progressive MODS

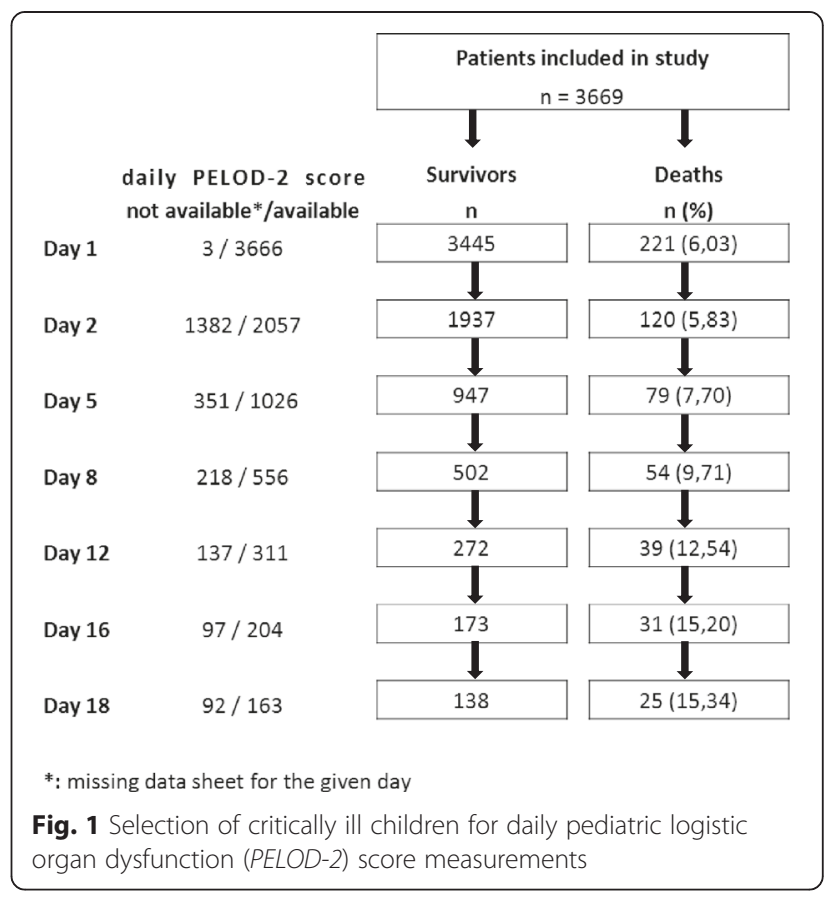

was reported in 343 patients $(9.3 \%$ of the whole population).

The PELOD-2 score on day 1 was a significant prognostic factor; the serial evaluation of the change in the dPELOD-2 score from day 1, adjusted for baseline value, demonstrated a significant odds ratio of death for each of the 7 days (Table 2). Median (IQR) values of dPELOD-2 scores in survivors and non-survivors are given in Table 3. The median maximum PELOD-2 score was $5(2-7)$ and differed between survivors and non-survivors $(5(2-7)$ and 15 (10-20), $p<0.0001)$. The AUC of the dPELOD-2 scores

Table 2 Serial evaluation of the change in the daily PELOD-2 score from day 1, adjusted for baseline value (PELOD-2 score on day 1)

\begin{tabular}{lccc}
\hline Variable & Odds ratio & $95 \% \mathrm{Cl}$ & $P$ value \\
\hline PELOD-2 score on day 1 & 1.51 & $1.44,1.57$ & $<.0001$ \\
Change in PELOD-2 score & & & \\
Day 1 to day 2 & 1.30 & $1.21,1.41$ & $<.0001$ \\
Day 1 to day 5 & 1.36 & $1.25,1.48$ & $<.0001$ \\
Day 1 to day 8 & 1.37 & $1.23,1.53$ & $<.0001$ \\
Day 1 to day 12 & 1.30 & $1.14,1.49$ & $<.0001$ \\
Day 1 to day 16 & 1.45 & $1.23,1.71$ & $<.0001$ \\
Day 1 to day 18 & 1.44 & $1.21,1.72$ & $<.0001$ \\
\hline
\end{tabular}

Odds ratio (OR) for death are given with $95 \% \mathrm{Cl}$. The cumulative OR of death was calculated as follows: (OR of pediatric logistic organ dysfunction (PELOD) score on day 1$) \times(\mathrm{OR}$ for change in score from day 1 to specified day). For example, for a child whose score is 10 on day 1 and 5 on day 12 , the change in score is -5 ; the OR for death would be $16.60=\left(\left(1.51^{10}\right) \times\left(1.3^{-5}\right)\right)$. For a child whose score is 4 on day 1 and 10 on day 8 , the change in score is 6 ; in this instance, the OR for death would be $34.37=\left(\left(1.51^{4} \times 1,37^{6}\right)\right)$ 
Table 3 Daily PELOD-2 scores among critically ill children: discrimination and calibration

\begin{tabular}{llllll}
\hline Day & $\begin{array}{l}\text { PELOD-2 score, survivors, } \\
\text { median (IQR) }\end{array}$ & $\begin{array}{l}\text { PELOD-2 score, non-survivors, } \\
\text { median (IQR) }\end{array}$ & $P$ value & $\begin{array}{l}\text { Discrimination } \\
\text { AUC (Cl 95 \%) }\end{array}$ & $\begin{array}{l}\text { Calibration }^{\text {a }} \\
\text { chi-square }(p \text { value) }\end{array}$ \\
\hline 1 & $4(2-6)$ & $12(8-18)$ & 0.0001 & $0.89(0.86,0.91)$ & $7.7(0.47)$ \\
2 & $3(2-5)$ & $8(5-15)$ & 0.0001 & $0.83(0.78,0.87)$ & $13.5(0.06)$ \\
5 & $3(2-5)$ & $7(5-10)$ & 0.0001 & $0.80(0.75,0.85)$ & $2.3(0.89)$ \\
8 & $3(2-5)$ & $7(5-9)$ & 0.0001 & $0.80(0.73,0.86)$ & $0.9(0.99)$ \\
12 & $3(2-5)$ & $6(5-8)$ & 0.0001 & $0.75(0.67,0.83)$ & $3.0(0.80)$ \\
16 & $3(2-5)$ & $6(4-8)$ & 0.0001 & $0.78(0.69,0.87)$ & $5.2(0.51)$ \\
18 & $3(2-5)$ & $6(5-8)$ & 0.0001 & $0.80(0.72,0.89)$ & $7.6(0.27)$ \\
\hline
\end{tabular}

${ }^{a}$ Hosmer-Lemeshow goodness-of-fit test. PELOD pediatric logistic organ dysfunction, $I Q R$ interquartile range, $A U C$ area under the receiver operating characteristic curve

at days $1,2,5,8,12,16$ and 18 in PICU, ranged from 0.75 (95\% CI $0.67,0.83)$ to 0.89 (95 \% CI 0.86, 0.91) indicating moderate to good discrimination (Table 3). The calibration assessed by the Hosmer-Lemeshow chi-square test ranged from a chi squared statistic of $13.5(p=0.06)$ to $0.9(p=0.99)$, indicating good calibration (Table 3$)$. For each of the 7 days under evaluation, mortality significantly increased with the number of organ dysfunctions (Table 4).

\section{Discussion}

In this study, we report that the dPELOD-2 scores calculated on the 7 days previously identified, had good discrimination and calibration. This study confirms that the progression of the severity of organ dysfunctions can be evaluated by measuring the dPELOD-2 scores during a specified set of days in PICU (admission and days 2, 5 , $8,12,16$ and 18). Our data not only showed that the PELOD-2 score on day 1 was a significant prognostic factor, but also that mortality was significantly higher in children in whom MODS worsened after day 1 as compared with those in whom MODS remained unchanged or improved. Thus, it makes sense to collect data daily on the severity of MODS in order to take into account this time factor $[15,16]$. It has been suggested that MODS scores are effective in quantifying the severity of each organ failure during the first ICU days, in adults

Table 4 Daily mortality (in percentage) related to organ dysfunction number

\begin{tabular}{llllllll}
\hline OD number & 0 & 1 & \multicolumn{1}{c}{2} & \multicolumn{1}{c}{3} & \multicolumn{1}{c}{4} & \multicolumn{1}{c}{5} & $P$ value $^{a}$ \\
\hline Day 1 & 0.7 & 0.8 & 3.0 & 9.6 & 38.0 & 70.2 & $<0.0001$ \\
Day 2 & 1.1 & 1.7 & 4.3 & 10.9 & 36.1 & 70.6 & $<0.0001$ \\
Day 5 & 0.6 & 3.2 & 8.2 & 20.1 & 28.6 & 50.0 & $<0.0001$ \\
Day 8 & 1.1 & 4.2 & 10.6 & 24.1 & 35.0 & 0 & $<0.0001$ \\
Day 12 & 3.7 & 4.9 & 15.7 & 27.6 & 25.0 & 0 & $<0.0001$ \\
Day 16 & 4 & 6.1 & 18.7 & 34.6 & 57.1 & NA & $<0.0001$ \\
Day 18 & 0 & 6.9 & 18.4 & 38.1 & 44.4 & NA & $<0.0001$ \\
\hline
\end{tabular}

${ }^{a}$ Mann-Whitney test. $O D$ organ dysfunction, NA not applicable
[17-19] as well as in children [20]. Furthermore, there is increasing evidence that the duration and progression of MODS influence outcome, indicating that MODS is a dynamic process [15, 20-28].

One can question if it is useful to monitor dPELOD-2 scores during a predetermined set days. Many studies have demonstrated that daily organ dysfunction monitoring can be a useful measurement to estimate the response to therapy in a group of patients [29-32]. The model that we proposed in this study, which includes 7 days distributed over the PICU stay, may represent the best balance between the workload of assessing daily scores and the optimal association with prognosis throughout the PICU stay. There have indeed been a number of studies in critically ill adults that support such an approach $[18,21,33]$. Moreover, in studies of long-stay ICU patients, severity scores at admission fail to predict mortality $[18,34]$. The late events cannot be predicted with admission or first-day predictive scores, and this suggest that for patients with prolonged ICU stay, the calculation of scores on later days, for example on days $8,12,16$ and 18 , may be useful.

What could be the practical applications of daily MODS scores? Some pediatric intensivists consider that an effective assessment of the severity of MODS, like the PELOD-2 score, is needed to correctly describe the clinical course in critically ill children [10]. The MODS score can be used as an outcome measure in trials conducted in the ICU [35, 36] and PICU [11, 30, 37, 38]. A recent study reported that delayed or inappropriate antimicrobial administration beyond $3 \mathrm{~h}$ from recognition of sepsis is an independent risk factor for prolonged organ failure and mortality [38]. Our study showed that the progression of the dPELOD-2 score added information to the PELOD-2 score for the whole PICU stay. All these data support the concept that the PELOD-2 score and its progression in the PICU can be outcome measures of interest in quality assessment activities and in clinical trials. New approaches, such as dynamic Bayesian networks, using the sequential organ failure assessment 
(SOFA) score, suggest that a sequence of organ dysfunctions can be predicted, which allows physicians to anticipate the development of MODS and help them undertake therapeutic decisions [39].

Strengths of this study include that it was prospective, and it was conducted in nine PICUs across two countries. It included a large number of critically ill children $(3,669)$ and a huge number of days in PICU (more than 7,900 days). Indeed, we have taken into account the dynamics of organ dysfunctions throughout the entire PICU stay.

This study is not without limitations. First, the dataset was collected 8 years ago and the case mix and mortality rate may have changed over this time period. Second, it was conducted in only two European countries (France and Belgium); our population is different from the US and UK populations [14]. Last, the number of deaths was quite low after 7 days in the PICU (there were 54 deaths in 557 patients with a length of stay in the PICU longer than 7 days), but higher than that in our previous study (33 deaths in 338 patients) [13]. Therefore, a large prospective study that is not country-specific would be useful to evaluate external validity of the PELOD-2 score; it should include more critically ill children with a long-term PICU stay and consider two groups of patients, those with a short PICU stay ( $<7$ days) and those with a long PICU stay ( $\geq 7$ days), in order to collect a sufficient number of deaths in each group [40]. Interestingly, a recent Portuguese study including 556 critically ill children admitted to PICU from January 2011 to December 2012 reported good discrimination (AUC 0.94) and calibration (after recalibration) of the PELOD-2 score [41].

\section{Conclusion}

This study shows that the progression of the severity of organ dysfunctions can be evaluated by measuring the dPELOD-2 score during a specified set of 7 days in the PICU. The serial evaluation of the change in the dPELOD-2 score from day 1, adjusted for the baseline value, demonstrated a significant odds ratio of death for each of the 7 days. The daily PELOD-2 score could be a helpful tool to stratify critically ill children enrolled in clinical trials, to describe their clinical course, to estimate therapeutic responses and to describe outcomes. It could also be used for epidemiologic and administrative purposes. External validation of the PELOD-2 score needs additional studies including more patients with a PICU stay $\geq 7$ days.

\section{Key messages}

- Progression of the severity of MODS can be evaluated by measuring the dPELOD-2 score during a specified period of 7 days in the PICU
- Daily PELOD-2 scores calculated on these days had good discrimination and calibration when used to predict short-term mortality

- In children in the PICU, the PELOD-2 score on day 1 is a significant prognostic factor

- New or progressive MODS during the PICU stay is associated with an increased risk of mortality

- The serial evaluation of the change in the dPELOD-2 score from day 1, adjusted for baseline value, demonstrated a significant odds ratio of death for each day

\section{Abbreviations}

AUC: area under the curve; dPELOD: daily pediatric logistic organ dysfunction; GFRUP: Groupe Francophone de Réanimation et Urgences Pédiatriques; ICU: Intensive care unit; IQR: interquartile range; MODS: multiple organ dysfunction syndrome; PELOD: pediatric logistic organ dysfunction; PICU: pediatric intensive care unit.

\section{Competing interests}

None of the authors has a financial relationship with a commercial entity that has an interest in the subject of this manuscript.

\section{Authors' contributions}

$F L$ and SL obtained funding. SL and FL conceived of and designed the study. SL and VD acquired the data. SL, VD, AD, JL and FL analyzed and interpreted the data. AD, VD and SL performed the statistical analysis. FL drafted the manuscript, and $F L, S L, J L, A D$ and $V D$ revised the manuscript critically for important intellectual content. All authors have given final approval of the version to be published. All authors agree to be accountable for all aspects of the work in ensuring that questions related to the accuracy or integrity of any part of the work are appropriately investigated and resolved.

\section{Acknowledgements}

This study was supported by the French Ministry of Health (Programme Hospitalier de Recherche Clinique $\left.n^{\circ} 1,997 / 122\right)$. GFRUP collaborators were: D. Biarent (Bruxelles, Belgium), R. Cremer (Lille, France); S. Dauger (Robert Debré-Paris, France), M. Dobrzynski (Brest, France), G. Emériaud (Grenoble, France), S. Renolleau (Trousseau-Paris, France), M. Roque-Gineste (Toulouse, France), D. Stamm, N. Richard (Lyon, France), and I.Wroblewski (Besançon, France).

\section{Author details}

${ }^{1}$ Pediatric Intensive Care Unit, Jeanne de Flandre University Hospital, 2 avenue Eugène Avinée, 59037 Lille, Cedex, France. 'EA 2694, Public Health: Epidemiology and Quality of Care, University of Lille 2, Lille, France.

${ }^{3}$ Department of Biostatistics, University of Medicine, Lille, France. ${ }^{4}$ Pediatric Intensive Care Unit, Sainte-Justine Hospital, Université de Montréal, Montréal, Canada.

Received: 13 June 2015 Accepted: 27 August 2015

Published online: 15 September 2015

\section{References}

1. Ferreira AM, Sakr Y. Organ dysfunction: general approach, epidemiology, and organ failure scores. Semin Respir Crit Care Med. 2011;32:543-51.

2. Cengiz P, Zimmerman JJ. Prelude to pediatric multiple organ dysfunction syndrome: the golden hours concept revisited. Pediatr Crit Care Med. 2003:4:263-4.

3. Marshall JC, Vincent JL, Guyatt G, Angus DC, Abraham E, Bernard G, et al. Outcome measures for clinical research in sepsis: a report of the 2 nd Cambridge Colloquium of the International Sepsis Forum. Crit Care Med. 2005;33:1708-16.

4. Proulx F, Gauthier M, Nadeau D, Lacroix J, Farrell CA. Timing and predictors of death in pediatric patients with multiple organ system failure. Crit Care Med. 1994;22:1025-31 
5. Wilkinson JD, Pollack MM, Glass NL, Kanter RK, Katz RW, Steinhart CM. Mortality associated with multiple organ system failure and sepsis in pediatric intensive care unit. J Pediatr. 1987;111:324-8.

6. Johnston J, Yi M, Britto M, Mrus J. Importance of organ dysfunction in determining hospital outcomes in children. J Pediatr. 2004;144:595-601.

7. Tantalean J, Leon R, Santos A, Sanchez E. Multiple organ dysfunction syndrome in children. Pediatr Crit Care Med. 2003;4:181-5.

8. Leclerc F, Leteurtre S, Duhamel A, Grandbastien B, Proulx F, Martinot A, et al. Cumulative influence of organ dysfunctions and septic state on mortality of critically ill children. Am J Respir Crit Care Med. 2005;171:348-53.

9. Vincent $J$, Moreno R. Clinical review: scoring systems in the critically ill. Crit Care. 2010;14:207.

10. Lacroix J, Cotting J. Severity of illness and organ dysfunction scoring in children. Pediatr Crit Care Med. 2005;6:S126-34

11. Sevketoglu E, Yildizdas D, Horoz OO, Kihtir HS, Kendirli T, Bayraktar S, et al. Use of therapeutic plasma exchange in children with thrombocytopenia-associated multiple organ failure in the Turkish thrombocytopenia-associated multiple organ failure network. Pediatr Crit Care Med. 2014;15:e354-9.

12. Leteurtre S, Duhamel A, Grandbastien B, Lacroix J, Leclerc F. Paediatric logistic organ dysfunction (PELOD) score. Lancet. 2006;367:897. author reply 900-892.

13. Leteurtre S, Duhamel A, Grandbastien B, Proulx F, Cotting J, Gottesman R, et al. Daily estimation of the severity of multiple organ dysfunction syndrome in critically ill children. CMAJ. 2010;182:1181-7.

14. Leteurtre S, Duhamel A, Salleron J, Grandbastien B, Lacroix J, Leclerc F, et al. PELOD-2: an update of the PEdiatric logistic organ dysfunction score. Crit Care Med. 2013;41:1761-73.

15. Ferreira FL, Bota DP, Bross A, Melot C, Vincent JL. Serial evaluation of the SOFA score to predict outcome in critically ill patients. JAMA. 2001;286:1754-8.

16. Zygun DA, Laupland KB, Fick GH, Sandham JD, Doig CJ. Limited ability of SOFA and MOD scores to discriminate outcome: a prospective evaluation in 1,436 patients. Can JAnaesth. 2005;52:302-8.

17. Metnitz PG, Lang T, Valentin A, Steltzer H, Krenn CG, Le Gall JR. Evaluation of the logistic organ dysfunction system for the assessment of organ dysfunction and mortality in critically ill patients. Intensive Care Med. 2001;27:992-8

18. Timsit JF, Fosse JP, Troche G, De Lassence A, Alberti C, Garrouste-Orgeas M, et al. Calibration and discrimination by daily Logistic Organ Dysfunction scoring comparatively with daily Sequential Organ Failure Assessment scoring for predicting hospital mortality in critically ill patients. Crit Care Med. 2002;30:2003-13.

19. Vincent JL, de Mendonca A, Cantraine F, Moreno R, Takala J, Suter PM, et al. Use of the SOFA score to assess the incidence of organ dysfunction/failure in intensive care units: results of a multicenter, prospective study. Working group on "sepsis-related problems" of the European Society of Intensive Care Medicine. Crit Care Med. 1998;26:1793-800.

20. Leteurtre S, Martinot A, Duhamel A, Proulx F, Grandbastien B, Cotting J, et al. Validation of the paediatric logistic organ dysfunction (PELOD) score: prospective, observational, multicentre study. Lancet. 2003;362:192-7.

21. Cappi SB, Sakr Y, Vincent JL. Daily evaluation of organ function during renal replacement therapy in intensive care unit patients with acute renal failure. J Crit Care. 2006;21:179-83.

22. Cook R, Cook D, Tilley J, Lee K, Marshall J. Multiple organ dysfunction: baseline and serial component scores. Crit Care Med. 2001;29:2046-50.

23. Doig CJ, Zygun DA, Fick GH, Laupland KB, Boiteau PJ, Shahpori R, et al. Study of clinical course of organ dysfunction in intensive care. Crit Care Med. 2004:32:384-90.

24. Jacobs S, Zuleika M, Mphansa T. The Multiple Organ Dysfunction Score as a descriptor of patient outcome in septic shock compared with two other scoring systems. Crit Care Med. 1999;27:741-4

25. Junger A, Engel J, Benson M, Bottger S, Grabow C, Hartmann B, et al. Discriminative power on mortality of a modified Sequential Organ Failure Assessment score for complete automatic computation in an operative intensive care unit. Crit Care Med. 2002;30:338-42.

26. Kilic YA, Yorganci K, Sayek I. Visualizing multiple organ failure: a method for analyzing temporal and dynamic relations between failing systems and interventions. Crit Care. 2007;11:417.

27. Moreno R, Vincent JL, Matos R, Mendonca A, Cantraine F, Thijs L, et al. The use of maximum SOFA score to quantify organ dysfunction/failure in intensive care. Results of a prospective, multicentre study. Working Group on Sepsis related Problems of the ESICM. Intensive Care Med. 1999;25:686-96.
28. Thandassery RB, Yadav TD, Dutta U, Appasani S, Singh K, Kochhar R. Dynamic nature of organ failure in severe acute pancreatitis: the impact of persistent and deteriorating organ failure. HPB. 2013;15:523-8.

29. Darmon M, Azoulay E, Thiery G, Ciroldi M, Galicier L, Parquet N, et al. Time course of organ dysfunction in thrombotic microangiopathy patients receiving either plasma perfusion or plasma exchange. Crit Care Med. 2006;34:2127-33.

30. Lacroix J, Hebert PC, Hutchison JS, Hume HA, Tucci M, Ducruet T, et al. Transfusion strategies for patients in pediatric intensive care units. N Engl J Med. 2007;356:1609-19.

31. Rivera-Fernandez R, Nap R, Vazquez-Mata G, Reis Miranda D. Analysis of physiologic alterations in intensive care unit patients and their relationship with mortality. J Crit Care. 2007:22:120-8.

32. Vincent JL, Baron JF, Reinhart K, Gattinoni L, Thijs L, Webb A, et al. Anemia and blood transfusion in critically ill patients. JAMA. 2002;288:1499-507.

33. Wagner DP, Knaus WA, Harrell FE, Zimmerman JE, Watts C. Daily prognostic estimates for critically ill adults in intensive care units: results from a prospective, multicenter, inception cohort analysis. Crit Care Med. 1994:22:1359-72.

34. Ferraris VA, Propp ME. Outcome in critical care patients: a multivariate study. Crit Care Med. 1992:20:967-76.

35. Marshall JC. Measuring organ dysfunction in the intensive care unit: why and how? Can J Anaesth. 2005;52:224-30.

36. Petros AJ, Marshall JC, van Saene HK. Should morbidity replace mortality as an endpoint for clinical trials in intensive care? Lancet. 1995;345:369-71.

37. Nguyen TC, Han YY, Kiss JE, Hall MW, Hassett AC, Jaffe R, et al. Intensive plasma exchange increases a disintegrin and metalloprotease with thrombospondin motifs-13 activity and reverses organ dysfunction in children with thrombocytopenia-associated multiple organ failure. Crit Care Med. 2008;36:2878-87.

38. Weiss SL, Fitzgerald JC, Balamuth F, Alpern ER, Lavelle J, Chilutti M, et al. Delayed antimicrobial therapy increases mortality and organ dysfunction duration in pediatric sepsis. Crit Care Med. 2014:42:2409-17.

39. Sandri M, Berchialla P, Baldi I, Gregori D, De Blasi RA. Dynamic Bayesian Networks to predict sequences of organ failures in patients admitted to ICU. J Biomed Inform. 2014;48:106-13.

40. Burns JP, Sellers DE, Meyer EC, Lewis-Newby M, Truog RD. Epidemiology of death in the PICU at five U.S. teaching hospitals*. Crit Care Med. 2014;42:2101-8.

41. Goncalves JP, Severo M, Rocha C, Jardim J, Mota T, Ribeiro A. Performance of PRISM III and PELOD-2 scores in a pediatric intensive care unit. Eur Pediatr 2015 (ahead of print).

\section{Submit your next manuscript to BioMed Central and take full advantage of:}

- Convenient online submission

- Thorough peer review

- No space constraints or color figure charges

- Immediate publication on acceptance

- Inclusion in PubMed, CAS, Scopus and Google Scholar

- Research which is freely available for redistribution 